\title{
Using Social Networking Analysis (SNA) to Analyze Collaboration between Students (Case Study: Students of Open University in Kupang)
}

\author{
Bonie Empy Giri \\ Faculty of Information Technology \\ Satya Wacana Christian University \\ Diponegoro Street, 52-60 Salatiga \\ 50711, Indonesia
}

\author{
Dany Manongga \\ Faculty of Information Technology \\ Satya Wacana Christian University \\ Diponegoro Street, 52-60 Salatiga \\ 50711, Indonesia
}

\author{
Ade Iriani \\ Faculty of Information Technology \\ Satya Wacana Christian University \\ Diponegoro Street, 52-60 Salatiga \\ 50711, Indonesia
}

\begin{abstract}
Open University (OU) in Indonesia was launched in 1984 to provide an opportunity for all citizens, both newly graduated high school and are already working to follow higher education. OU learning system is flexible; students learn independently and there is no study completion deadline. Learning material in the form of multimedia (print, audiocassette, or CD-ROM) and delivered through the post office, radio, TV, or internet. Realizing that the interaction between students can provide encouragement or support for the understanding of the material being studied, then OU facilitates interaction through several meetings scheduled. The purpose of this study is to analyze the social interactions between students in the city of Kupang. This study uses a Social Network Analysis (SNA) tool to analyze and map the interactions of individuals in the network. The analysis showed that there is a social relationship between them, but of little value. The results of this analysis support the importance of Open University to facilitate regular meetings between students to encourage collaboration between them.
\end{abstract}

Keywords

Open University, Social Network Analysis (SNA), Collaboration

\section{INTRODUCTION}

Open University (OU) in Indonesia provides an open and distance higher education. In terms of student body, OU is one of the big universities in the world. The number of its students currently exceeds 580,000 students. The remote and open learning system of $\mathrm{OU}$ is very effective in increasing the coverage and equitable access to higher education for all Indonesian citizens, including those living in remote areas. Since it was established in 1984, OU received a mandate from the government to provide a very broad opportunity for all citizens of Indonesia, either newly graduated high school or are already working to follow higher education, regardless of their social background, economic, age, and location of residence.

OU learning systems also provides flexible learning opportunities, especially for those who do not have the chance to follow the system of higher education or for those who have constraint following the lecture in person. The characteristics of OU learning system are that students learn independently and are not limited by study completion deadline. Learning material is in the form of multimedia (print, audiocassette, or CD-ROM) and delivered through the post office, radio, TV, or internet. However, self-learning often provide difficulties for OU students, because there is no interaction between them that can provide encouragement or support to understand the material being studied. For this purpose, OU encourages interactions between students through a series of meetings scheduled.

The purpose of this study is to analyze the behavior of social interaction between OU students who lives in Kupang, the capital of East Nusa Tenggara Province. This study uses a social network analysis tool to analyze and map interactions of individuals in the network.

\section{LITERATURE REVIEW}

\subsection{Previous Research}

Some researchers have used SNA to analyze and map the relationships that occur in educational institutions, e.g. the use of SNA in mapping the learning process at LPIA Tambun [1]. There is also the use of SNA to evaluate programs aimed at improving school performance through cooperation among teachers [2]. While [3] used SNA to analyze knowledge sharing and interaction in cooperative learning groups. In this study, they used SNA to increase the efficiency of organizational knowledge management structure of team learning.

The use of SNA for visualization that supports creativityenabling pedagogical practices was found in [4]. They provide initial case study of how social network analysis can be useful for evaluating student learning networks and creative capacity. They also outline how the evaluative resources enable educators to design and implement creativity-enabling pedagogical practice.

A research on the dynamics of social networks in university coursework is also found in [5]. They found that the interaction between the participants could be described in terms of measures such as the frequency of qualitative and quantitative participation, evidence of the quality of reflection in the post, and the depth of analysis. The qualitative analysis provides a valuable insight into the nature and effectiveness of the online learning experience.

\subsection{Distance Learning}

Researchers have long recognized the importance of student interaction in the teaching and learning process. This is necessary in building a person's cognitive processes. If a person cannot effectively share knowledge among members of the group, then it can lead to poor learning outcomes [6]. Research in [7] showed that the distance-learning students need support and motivation in addition to the content subject matter, and without it, their success is limited. The relationship between students' emotional intelligence, social ties and their interaction in the online learning environment was studied in [8]. Their results showed a positive relationship 
between students' social ties and interactions. Students who have high emotional intelligence have greater levels of social cohesion in online learning. Specifically, individuals with a higher ability in emotional feeling tend to be more attached to the peers in the online learning environment.

\subsection{Social Network and Social Network Analysis (SNA)}

Social networks exist in society. A social network is a social structure consisting of a set of social actors, individuals or organizations, and a set of relationships between the actors [9]. Social network perspective provides a method for analyzing the structure of a social entity as a whole as well the theory that explains the patterns observed in this structure.

Social network analysis is a tool for analyzing the structure of social relations within a group. SNA reveal patterns, map the relationship between the individual, and simultaneously visualize the relationships between the actors. Some benefits of SNA can be seen in [1].

There are three main categories of elements in SNA, namely:

- Groups. A group consists of a set of actors. Actors can be individuals in a project or in a company division, or it could be a set of organizations in an industry.

- Interactions. Attributes refer to the features that are owned by an actor. Attributes can help determine whether there are systemic factors that affect the interaction between individuals. Attributes can include job title, gender, or location of the individual.

- Attributes. Attributes refer to the features that are owned by an actor. Attributes can help determine whether there are systemic factors that affect the interaction between individuals. Attributes can include job title, gender, or location of the individual.

SNA provides several methods of measurement to examine the relationship between individuals in a group include:

- Degree centrality. Degree centrality measures the number of actors who are connected to an individual. This measure indicates the position of an individual within the network

- Betweeness centrality. This measure shows the role of an individual as a liaison with other actors and his/her potential to coordinate communication within the group. It indicates the frequency of an actor lies in the shorter paths between actors in the network.

- Closeness centrality. This measure indicates the efficiency of an actor's role as a facilitator of integration in the network. It counts the number of steps needed on average for an actor to reach other actors in the network. An individual with the highest score is the most efficient actor. This individual can disseminate information faster, cheaper and fewer intermediaries.

\section{METHODOLOGY}

This study used a questionnaire survey method. Data were collected from 56 OU students who live in the city of Kupang, East Nusa Tenggara. The selection of respondents started with a few individuals who are OU students. Then through them, other students who become their friends can be traced.

The questionnaires then were tabulated in the relationship matrix and the attribute matrix. The data are the analyzed using UCINET 6 and NetDraw application developed by Analytic Technologies [10].

\section{RESULTS AND DISCUSSION}

The following sections will discuss in detail the results of calculations using UCINET 6 and NetDraw applications to various statistical measures and the centrality of the individuals in the network.

\subsection{Density}

Table 1 shows the results of calculations using UCINET 6 for descriptive statistics. The coefficient sum in the third line of Table 1 indicates that there are 119 ties occur in the network. $\mathrm{N}$ of Obs in the tenth row indicates that there are 3080 possible ties in the network.

The average of ties (density) in the network is $3.9 \%$, which means that density is less than $50 \%$. There is no missing value ( $\mathrm{N}$ Missing), which means that each individual has relationship with other individuals. With significant differences between the ties that occur and the total ties that can happen, it can be concluded that the ties between the individuals in these networks are weak.

Table 1. Descriptive Statistics

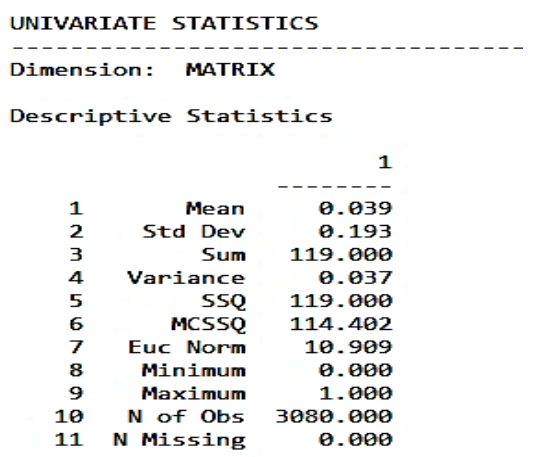

\subsection{Influential Individuals}

\subsubsection{Degree Centrality}

Table 2 shows the descriptive statistics of degree centrality. There are 56 people in the network, but this table only shows a few individuals who have a high degree of centrality. In this table, individual \# 4 is the individual with the highest centrality value with a value of nine, either for outdegree or indegree. This suggests that this individual send information to nine individuals in the network and receive information from other nine individuals as well.

In terms of the overall degree, the combination of outdegree and indegree, individual \# 4 has the highest degree of all the individuals in the network. This means that this individual has big influence both in terms of conveying information as well as in terms of receiving information from other individuals. Therefore, this individual has a very important position in the collaboration between individuals.

Figure 1 shows the sociogram of individuals based on their degree centrality. The sizes of their symbols indicate their centrality degree. Individual \#4 with a red box is the most 
influential individual in terms of sending and receiving of information. This figure also shows the individuals with a limited number of relationships, such as individual \#28, \#29, \#33 or \#51. These individuals only have one relationship, either sending or receiving information.

\section{Table 2. Descriptive Statistics}

FREEMAN'S DEGREE CENTRALITY MEASURES

\section{Diagonal valid? NO \\ Model : \\ NO \\ Input dataset: ucinet matriks revisi terbaru}

$\begin{array}{rrrrr} & \begin{array}{r}1 \\ \text { OutDegree }\end{array} & \begin{array}{r}2 \\ \text { InDegree }\end{array} & \begin{array}{r}3 \\ \text { NrmOutDeg }\end{array} & \begin{array}{r}4 \\ \text { NrmInDeg }\end{array} \\ 4 & 9.000 & 9.000 & 16.364 & 16.364 \\ 2 & 4.000 & 4.000 & 7.273 & 7.273 \\ 45 & 4.000 & 4.000 & 7.273 & 7.273 \\ 7 & 4.000 & 2.000 & 7.273 & 3.636 \\ 9 & 4.000 & 4.000 & 7.273 & 7.273 \\ 5 & 3.000 & 2.000 & 5.455 & 3.636 \\ 50 & 3.000 & 3.000 & 5.455 & 5.455 \\ 11 & 3.000 & 3.000 & 5.455 & 5.455 \\ 6 & 3.000 & 3.000 & 5.455 & 5.455 \\ 10 & 3.000 & 2.000 & 5.455 & 3.636 \\ 3 & 3.000 & 2.000 & 5.455 & 3.636 \\ 47 & 3.000 & 3.000 & 5.455 & 5.455 \\ 41 & 3.000 & 4.000 & 5.455 & 7.273 \\ 39 & 3.000 & 3.000 & 5.455 & 5.455 \\ 37 & 3.000 & 3.000 & 5.455 & 5.455 \\ \cdots & \cdots & \cdots & \cdots & \cdots \\ \cdots & \cdots & \cdots & \cdots & \cdots\end{array}$

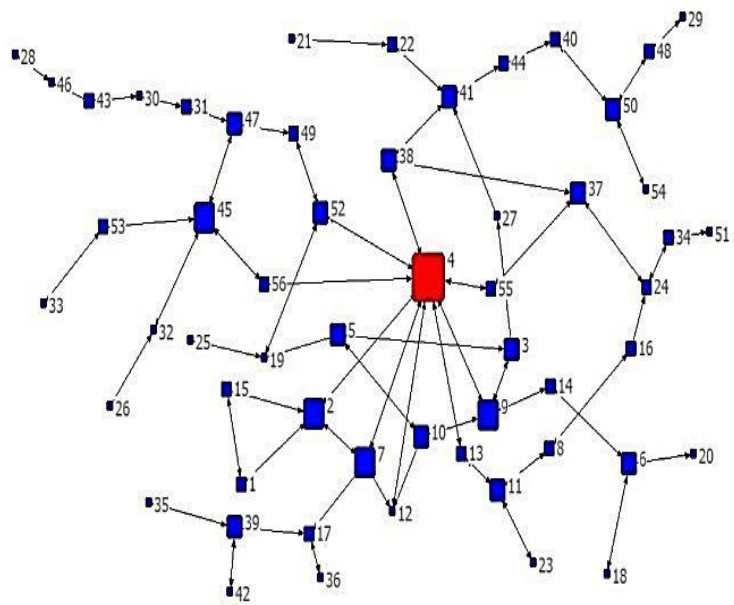

Fig 1. Sociogram of individuals based on degree centrality

From the picture above it can be seen that the existing network each have an individual as a node (symbol big blue box) that will pass the information on to individuals or 4 as the central of the network, the vertices of each individual network is an individual who does communication with more than one person.

Overall the existing communication network is a communications network that is radial networks in which all communication between individuals is centered on the individual who has the greatest value of degree centrality (individual 4 symbols red box). The picture above can be seen that the existing network each have an individual as a node (symbol big blue box) that will pass the information on to individuals or 4 as the central of the network, the vertices of each individual network is an individual who communicates with more than one person.

\subsubsection{Closeness Centrality}

Table 3 shows the results of closeness centrality calculation of several individuals in the network. Incloseness indicates how close other individuals to an individual in the network, while Outcloseness indicates how close an individual to the other individuals in the network. From the calculation, individual \# 4 has the highest value for both incloseness and outcloseness. The second position is occupied by individual \# 38; asymmetrical network makes values of incloseness and outcloseness different.

The results of these calculations indicate that individual \# 4 has the minimum distance to other individuals in the network. In other words, this individual is able to disseminate information quickly to many individuals.

Table 3 also shows that individual \# 17 has Incloseness value which is greater than his (her) outcloseness value. This means that other individuals in the network require more steps to this individual than the number of steps from this individual to other individuals in the network.

Table 3. The results of closeness centrality calculations CLOSENESS CENTRALITY

Method: Reciprocal Geodesic Distances

Closeness Centrality Measures

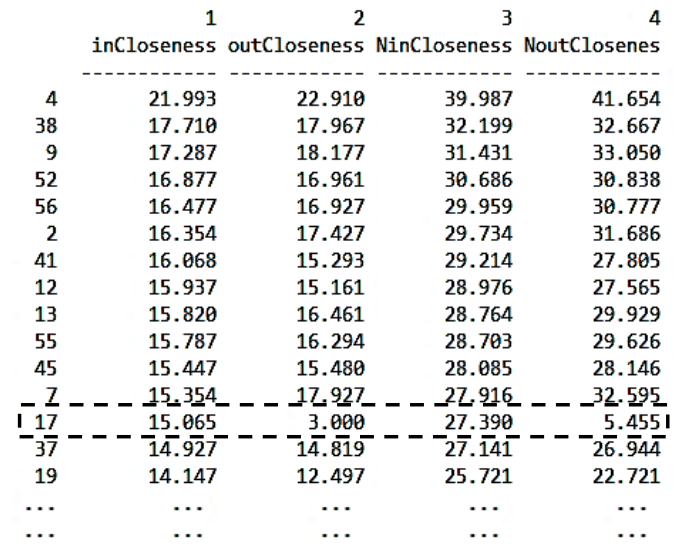

\subsubsection{Betweeness Centrality}

Table 4 shows the results of calculations betweeness centrality of several individuals in the network. From these results, individual \# 4 has the highest betweeness centrality, followed by individual \#38 and \#41. These figures indicate that the three individuals have a favorite position in the network, since many individuals depend on them to make connections with other individuals. In other words, these three individuals have a variety of alternative shortest paths to reach other individuals in conveying information or receive information. This occurs because the three individual occupy the position as an intermediary for individuals to connect with other individuals.

On the other hand, individuals \# 14, \# 47 and \# 7 have betweeness centrality values, which are much smaller than individual \# 4. This means that these three individuals do not have a strategic position to become an intermediary for individuals to connect with other individuals in the network. 
Table 4. The results of betweeness centrality calculations FREEMAN BETWEENNESS CENTRALITY

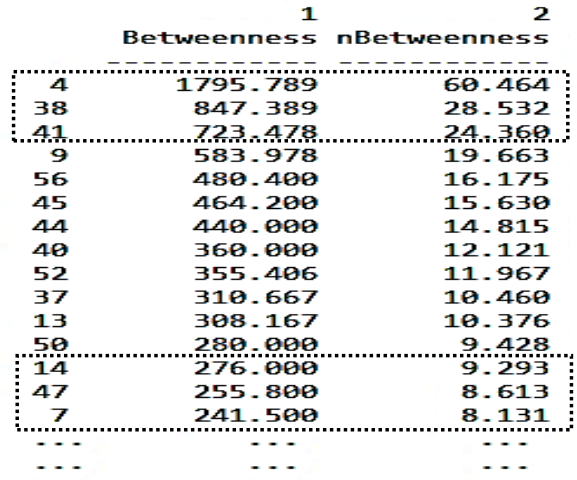

\subsection{Relationship by Gender}

Figure 2 shows the relationship based on gender where the red boxes indicate women and the blue circle are men. From Figure 2, it is obvious that the number of women (45 individuals) is greater than the number of men (11 individuals).

In addition to dominating the network, women are more concentrated in the center of network than men. Women also appear more active than men do. They communicate not only with their peers but also with the opposite gender. Women appear as individuals who give as well as receive information, while men tend to be the recipient of information. Women also have more than one individual relationships, while men mostly just with one individual (indicated by ellipses with dashed lines and show in table 5).

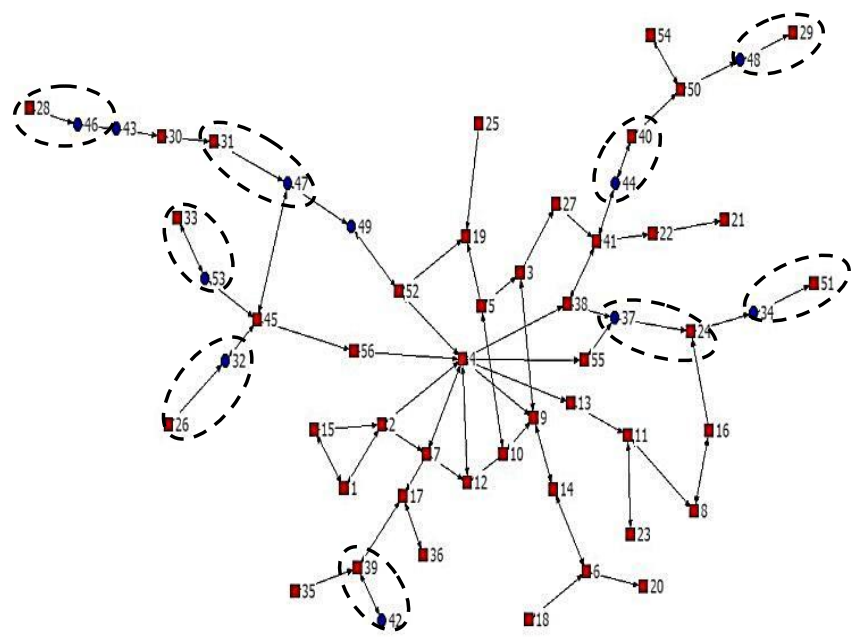

Fig 2. Communication between genders

Table 5. Communication Individual opposite gender

\begin{tabular}{|l|c|}
\hline No. & Number of Individual \\
\hline 1. & 28 with 46 \\
\hline 2. & 31 with 47 \\
\hline 3. & 33 with 53 \\
\hline 4. & 32 with 26 \\
\hline 5. & 39 with 42 \\
\hline 6. & 37 with 24 \\
\hline 7. & 34 with 51 \\
\hline 8. & 44 with 40 \\
\hline 9. & 48 with 29 \\
\hline
\end{tabular}

\subsection{Relationship Based on Study Program}

This study focused only on students of two study programs, namely primary education, and secondary education. In figure 3 , green triangle symbols indicate individuals of basic education program, while blue circle symbols indicate individuals of secondary education program.

Figure 3 shows that individuals tend to be associated with those who have the same study program, except individuals \#26, \#28, and \#29 (table 6). These three individuals are isolated individuals who only have a relationship with individuals of different study program.

It is interesting to note that although there are two study programs, but individual \#4, who is derived from secondary education program, is the central individual bridging individuals of both study programs. In addition, there are no study program can claim dominant, because individuals of each study program give and receive information from both sides.

Referring to the relationship between individuals of the two study programs, we can conclude that the collaborative relationships that occur are not always based on academic goals, such as working together for completing course assignments, but also non-academic. In addition, the patterns of these relationships suggest that not all students get to know colleagues in their study program.

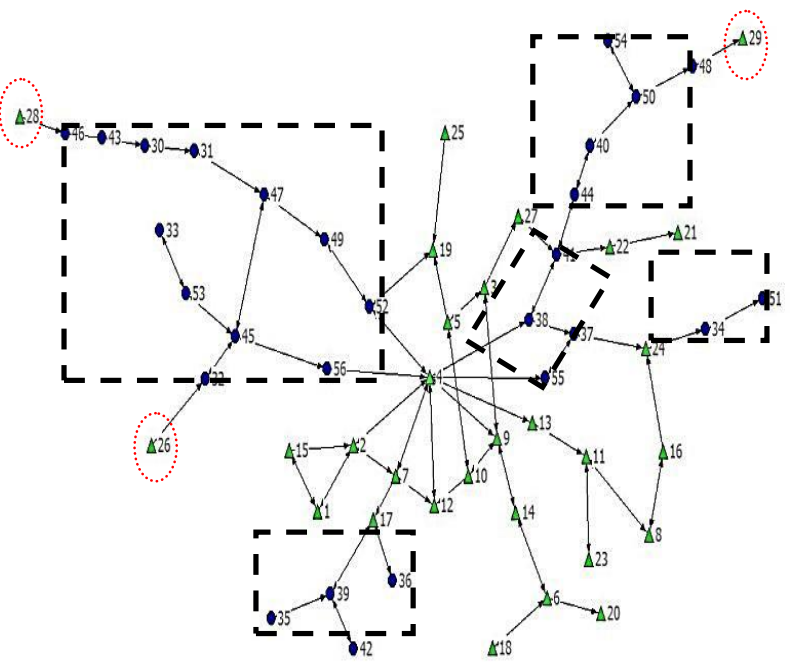

Fig 3. Communication between study program

Table 6. individuals have a relationship with individuals of different study program

\begin{tabular}{|c|c|}
\hline No & Number of individual \\
\hline 1. & 28 with 48 \\
\hline 2. & 26 with 32 \\
\hline 3. & 29 with 48 \\
\hline
\end{tabular}

\subsection{Relationship Based on Location of Residence}

To see how the pattern of relationships based on student residence, the location of their residence is divided in 12 locations in the city area of Kupang. Table 7 shows the group ids, residence locations, individual ids, and color symbols.

Figure 4 shows that the relationship based on residence does not have a clear pattern, because individuals do not have a corresponding relationship with the location of their 
residence. This can happen because the influence of social media or communications technology, in which individuals can communicate without having to meet face to face. For example, individual \# 46 living in Penfui (blue color) has relationship with individual \# 43 (green color) living in Oepura. In terms of location, the distance between their locations is quite far apart, about $10 \mathrm{~km}$. This is only possible because of good communication facilities. Individual \# 4 is individual who is central in the network, however he lives in Baumata, which is far outside the city center.

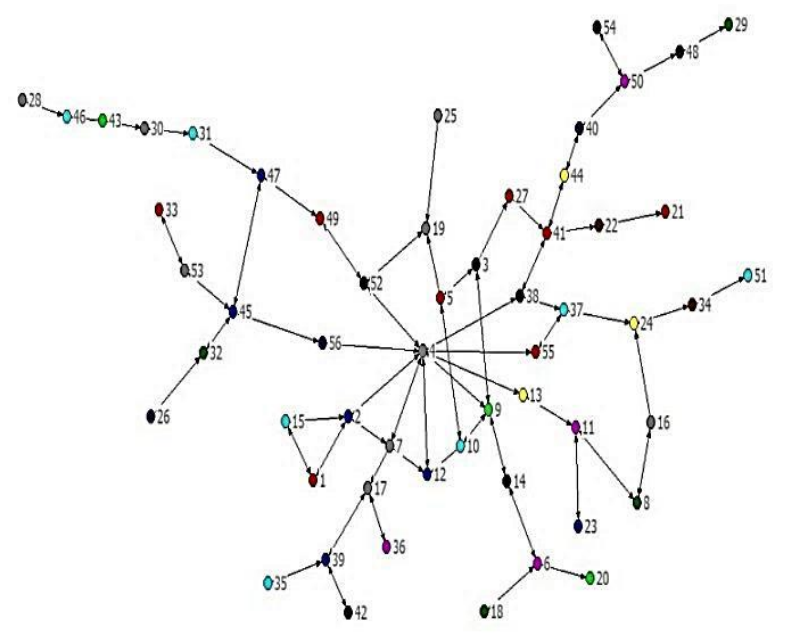

Fig 4. Individual relationships based on residence

Table 7.Goup ids, residence locations, individual ids, and color symbols

\begin{tabular}{|c|l|c|c|c|}
\hline Group & Location & Individual & $\begin{array}{c}\text { Number of } \\
\text { Individual }\end{array}$ & Color \\
\hline 1 & Kuanino & $\begin{array}{c}3,14,38,42, \\
48,52,54\end{array}$ & 7 & $\bigcirc$ \\
\hline 2 & Oesapa & $\begin{array}{c}1,5,21,27, \\
33,41,49,55\end{array}$ & 8 & $\bigcirc$ \\
\hline 3 & Walikota & $\begin{array}{c}17,25,30,53 \\
10,15,31,35, \\
37,46,51\end{array}$ & 7 & $\bigcirc$ \\
\hline 4 & Penfui & $\begin{array}{c}4,12,23,39,45, \\
47\end{array}$ & 6 & $\bigcirc$ \\
\hline 5 & Oebufu & $5,16,19,28$ & 5 & $\bigcirc$ \\
\hline 6 & Baumata & $4,7,3,50$ & 4 & $\bigcirc$ \\
\hline 7 & Kelapa & $6,11,36,50$ & $\bigcirc$ \\
\hline 8 & Oebobo & $26,40,56$ & 3 & $\bigcirc$ \\
\hline 9 & Oepura & $9,20,43$ & 3 & $\bigcirc$ \\
\hline 10 & Naikoten & 22,34 & 2 & $\bigcirc$ \\
\hline 11 & Bakunase & $13,24,44$ & 3 & $\bigcirc$ \\
\hline 12 & Lain-lain & $8,18,29,32$ & 4 & $\bigcirc$ \\
\hline
\end{tabular}

\subsection{Relationships Based on the Number of Credit Points}

This study also looked at how the relationship of individuals based on the number of credit points. The goal is to determine whether there is a pattern of collaboration between students based on their credit points. For this purpose, the number of credit points is categorized into four sections as shown in Table 8 .
Figure 5 shows the relationship of individuals with different number of credit points. From this figure, it is clear that individuals do not always relate to other individuals because of similarity of the total number of their credit points. Some individuals who have a low number of credit points have relationships with individuals who have a higher number of credit points, e.g. individual \#28 with \# 46, or individual \#33 with \#53. In addition, individual \# 4 who is the central individual in the network, has a number of credit points in category 3 (91-120 credit points). This individual has a relationship with the individual \# 12 , which is in category 1 (10-45 credit points).

Table 8. Group, number of credit points, color

\begin{tabular}{|c|c|c|}
\hline Group & $\begin{array}{c}\text { Credit } \\
\text { points }\end{array}$ & Color \\
\hline 1 & $10-45$ & $\bigcirc$ \\
\hline 2 & $46-90$ & $\bigcirc$ \\
\hline 3 & $91-120$ & \\
\hline 4 & $>121$ & $\bigcirc$ \\
\hline
\end{tabular}

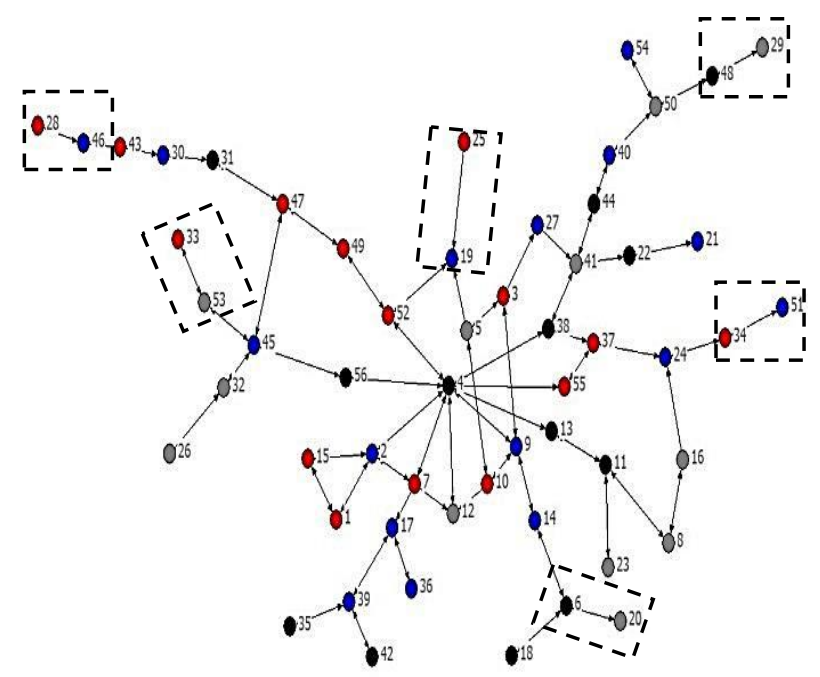

Fig 5. Communication based on the number of credit points

\section{CONCLUSION}

In this study, the female students are more dominant than the male students are. The female students are not only dominant in number, but also in relationship with other people. From the pattern of relationships between students, female students' relationship pattern was more intensive than the relationship patterns of male students. In other words, the female students are actually the driving force of the interaction in this network. However, interactions between students in general are not too strong. Most students only have a limited relationship with another student. This could be due to lack of opportunity for students to meet and to know each other.

The results of this study also indicate that the relationship between OU students in Kupang is not always based on academic issues, such as working together for completing course assignments, but also non-academic. This is evident from the presence of the relationship between students with different study programs and different number of credit points. In addition, the location or distance of residence does not influence the relationships between students. This could be caused by the availability of facilities such as hand phone 
and internet communications, which have removed the constraints of space and time.

Table 9. Comparative each relations

\begin{tabular}{|c|c|c|}
\hline No & Relation & Characteristics \\
\hline 1. & Relation by Gender & $\begin{array}{l}\text { - women also have more than } \\
\text { one individual; } \\
\text { men mostly just with one } \\
\text { individual. }\end{array}$ \\
\hline 2. & $\begin{array}{l}\text { Relationship Based } \\
\text { on Study Program }\end{array}$ & $\begin{array}{l}\text { - relationships suggest that not } \\
\text { all students get to know } \\
\text { colleagues in their study } \\
\text { program; } \\
\text { - there are no study program } \\
\text { can claim dominant. }\end{array}$ \\
\hline 3. & $\begin{array}{l}\text { Relationship Based } \\
\text { on Location of } \\
\text { Residence }\end{array}$ & $\begin{array}{l}\text { - does not have a clear pattern; } \\
\text { relationship without having to } \\
\text { meet face to face (social } \\
\text { media or communications } \\
\text { technology). }\end{array}$ \\
\hline 4. & $\begin{array}{l}\text { Relationships Based } \\
\text { on the Number of } \\
\text { Credit Points }\end{array}$ & $\begin{array}{l}\text { - does not have a clear pattern; } \\
\text { have a relationship different } \\
\text { number of credit points }\end{array}$ \\
\hline
\end{tabular}

\section{REFERENCES}

[1] Febry de Fretes. 2012. Application of Social Network Analysisfor Mapping Patterns of the Learning Processin LPIA Tambun. IJCSI International Journal of Computer Science Issues, Vol. 9, Issue 3, No 1, May 2012ISSN (Online): 1694-0814.

[2] Penuel, W.R., Sussex, W., Korbak, C., and Hoadley, C.2006. American Journal of Evaluation, Vol. 27 No. 4, December 2006 437-451
[3] Hantian, W, dan Furong, W. 2011. Cooperative Learning Using Social Network Analysis. Information and Management EngineeringCommunications in Computer and Information Science Volume 235, 2011, pp 511-517

[4] Dawson, S., Tan, J.P.L., and McWilliam, E. 2011.Measuring creative potential: Using social networkanalysis to monitor a learners' creative capacity.Australasian Journal of Educational Technology 2011, 27(6), 924-942

[5] Shea,P., Hayes, S., Vickers,J., Cohen, M. Gozza., Uzuner, S., Mehta,R. et al, "A Reexamination of the Community of Inquiry Framework: Social Network and Content Analysis", Internet \& Higher Education [serial on the Internet], vol. 13, no. 1/2, Jan. 2010, pp. 10-21

[6] Soller, A. (2004). Computational modeling and analysis of knowledge sharing in collaborative distance learning. User modeling and user adapted interaction, 14, 351381.

[7] Williams, P. (2006). On-demand tutoring in distance education: Intrinsically-motivated, scalable interpersonal interaction to improve achievement, completion, and satisfaction. Dissertation abstracts international section A: Humanities and social sciences, 66, 11-A, 3933.

[8] Han, H., \& Johnson, S. D. (2012). Relationship between students' emotional intelligence, social bond, andinteractions in onlinlearning. Educational Technology \& Society, 15(1), 78-89

[9] Wasserman S, Faust K (1994) Social network analysis. Cambridge University Press, New York.

[10] Borgatti, S.P., Everett, M.G. and Freeman, L.C. 2002. Ucinet for Windows: Software for Social Network Analysis. Harvard, MA: Analytic Technologies 